\title{
Sacral Squamous Cell Carcinoma in Psoriatic Lesion: Reconstruction by Combined Gluteal Turnover and Fasciocutaneous Flap
}

\author{
Naveen kumar* and Shobhit Gupta \\ Department of burns, Plastic and Maxillofacial Surgery, India
}

*Corresponding author: DR. Naveen kumar, Department of Burns, Plastic and Maxillofacial Surgery, R.M.L Hospital and PGIMER, New Delhi, India

\begin{abstract}
Introduction: Studies have shown incidence of $1-5 \%$ SCC development in old psoriatic plaques out of which sacrum is rare site. In our case we excised a post psoriatic SCC and reconstructed it with a gluteus maximus turnover flap on one side along with fasciocutaneous only VY advancement flap on other side.

Case Representation: A 45-year-old gentleman was presented with an ulceroproliferative growth on sacral region over the pre-existing lesions of psoriasis for the last 6 months. The lesions were firm to hard in consistency, fixed to underlying fascia and muscle, bone was free, there was sero-sanguineous oozing from the lesions. Histopathology was suggestive of well-differentiated squamous cell carcinoma (SCC). Lesion was excised with $2 \mathrm{~cm}$ margin, in depth the level of excision was till periosteum of sacrum. The true soft tissues defect was around $15 \mathrm{~cm}$ by $10 \mathrm{~cm}$ with exposed sacrum in the middle part. On right side gluteus maximum muscle only turnover flap was raised, and on left side VY faciocutaneous flap was raised to cover the defect. Patient was discharged on $10^{\text {th }}$ Post-operative day.
\end{abstract}

Conclusion: We conclude that long standing psoriatic ulcer should always be assessed for conversion into malignancy. Gluteal maximus muscle flaps can be used with various combinations with fasciocutaneous flaps for reconstruction of sacral defects.

Keywords: Psoriasis; sacral defects; squamous cell carcinoma; Gluteal maximus muscle flap

\section{Introduction}

Psoriasis is regarded as an autoimmune disease in which genetic and environmental factors have a significant role. The name of the disease is derived from Greek word "psora" which means "itch" [1]. Patients with psoriasis are at an increased risk of developing cutaneous malignancy; especially non-melanoma skin cancers and lymphoproliferative disorders [2]. Studies have shown incidence of 1 - $5 \%$ SCC development in old psoriatic plaques out of which sacrum is rare site $[3,4]$. Complex tissue defects following excision of sacral tumor often present a clinical challenge to the reconstructive surgeon. There are variety of gluteal flaps which have been reported but combination with a facsciocutaneous flap for a large defect reconstruction makes it a rare entity. In our case we excised a post psoriatic SCC and reconstructed it with a gluteus maximus turnover flap on one side along with fasciocutaneous only VY advancement flap on other side.

\section{Case Presentation}

A 45-year-old gentleman was presented to our hospital with 15 years history of psoriasis over back and over sacral region. For the last 6 months; he had developed an ulceroproliferative growth on sacral region over the pre-existing lesions of psoriasis. Before coming to us; he had received only homeopathic treatment without any relief. There was no family history of psoriasis or of malignancy. Physical examination revealed dirty white ulceroproliferative growths over the psoriatic plaques; measuring around $10 \mathrm{~cm}$ by 5 $\mathrm{cm}$ on sacral region extending from $2 \mathrm{~cm}$ above the superior border of sacrum and $2 \mathrm{~cm}$ superior to anal opening inferiorly; $7 \mathrm{~cm}$ on the right side; $3 \mathrm{~cm}$ on the left side from mid line. The lesions were firm to hard in consistency; fixed to underlying fascia and muscle; bone was free; there was sero-sanguineous oozing from the lesions. The skin surrounding the growths showed well-defined erythematous plaques with silvery scales (Figure 1). 


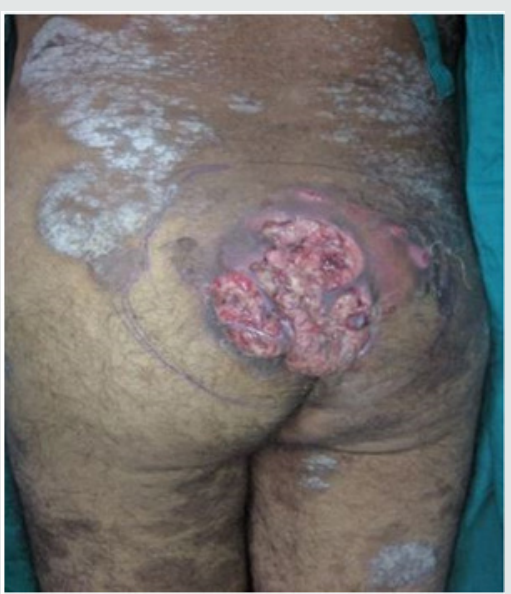

Figure 1: Figure showing sacral SCC with psoriatic lesions.

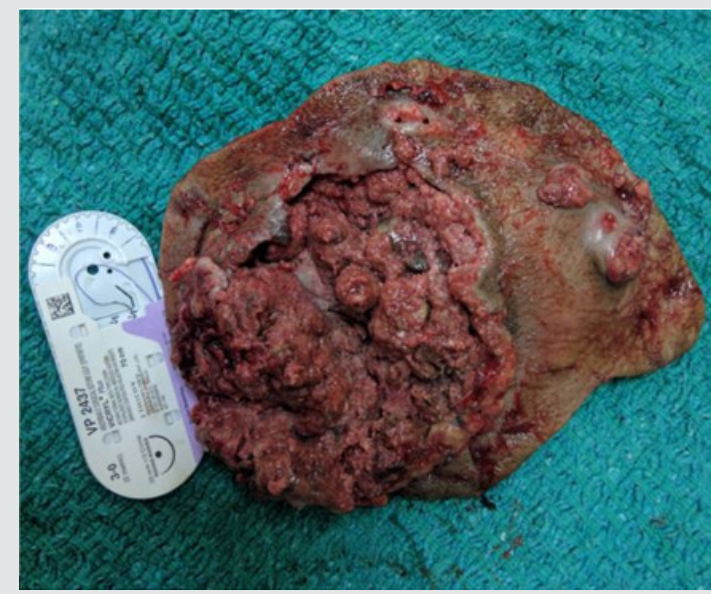

Figure 2: Excised lesion.

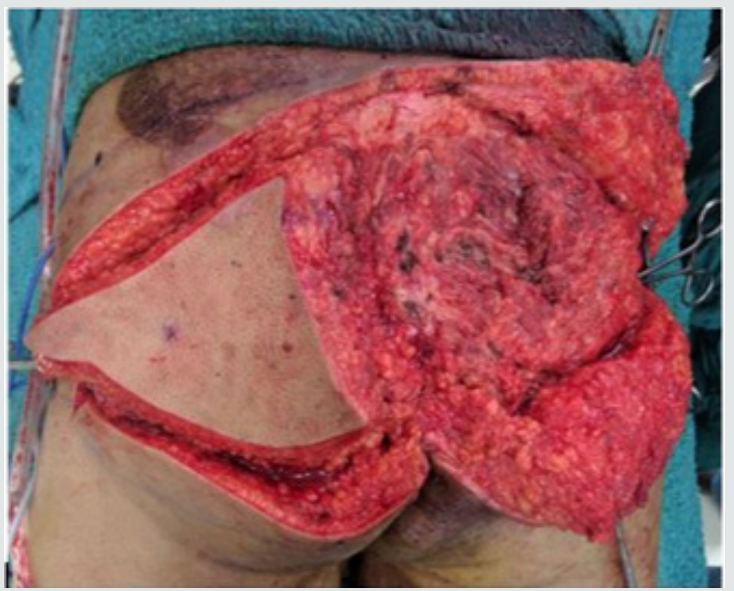

Figure 3: Figure showing Gluteal turnover and fasciocutaneous flap.

Systemic examination revealed nothing relevant. The X-ray lumbosacral spine was normal. Non-contrast CT showed extension of tumour till muscle. Histopathology was suggestive of welldifferentiated squamous cell carcinoma (SCC). In prone position under general anaesthesia the lesion was excised with $2 \mathrm{~cm}$ margin in depth the level of excision was till periosteum of sacrum
(Figure 2). The true soft tissues defect was around $15 \mathrm{~cm}$ by 10 $\mathrm{cm}$ with exposed sacrum in the middle part. On right side gluteus maximus muscle only turnover flap was raised; and on left side VY faciocutaneous flap was raised to cover the defect. Skin grafting was done to cover the muscle (Figures $3 \& 4$ ). Suction drain was kept under the turnover muscle flap. Patient was nursed in prone position; drain was removed on 5th post-operative day. There was minor graft loss which healed secondarily (Figure 5). Patient was discharged on $10^{\text {th }}$ POD in stable and mobile condition. Patient was followed till 3 months with no other complication.

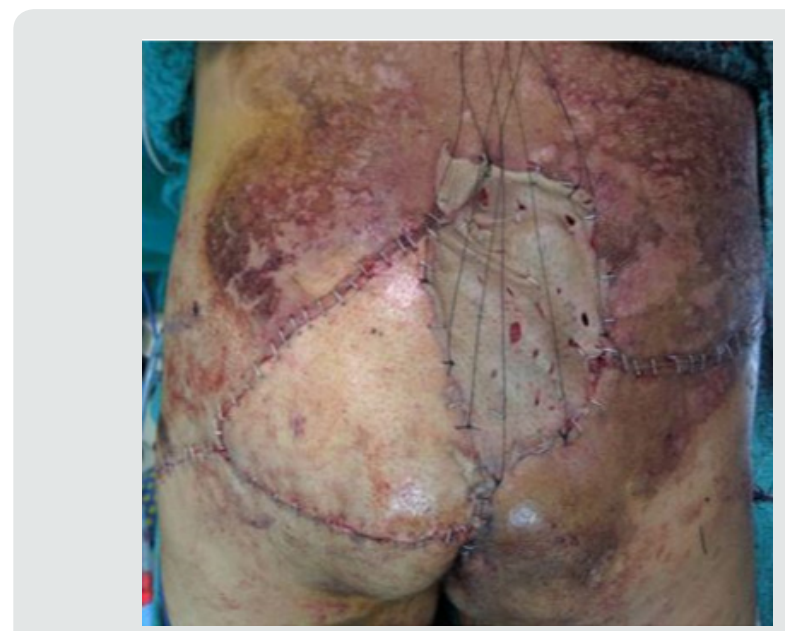

Figure 4: Figure showing flap coverage of the sacral defect with skin graft.

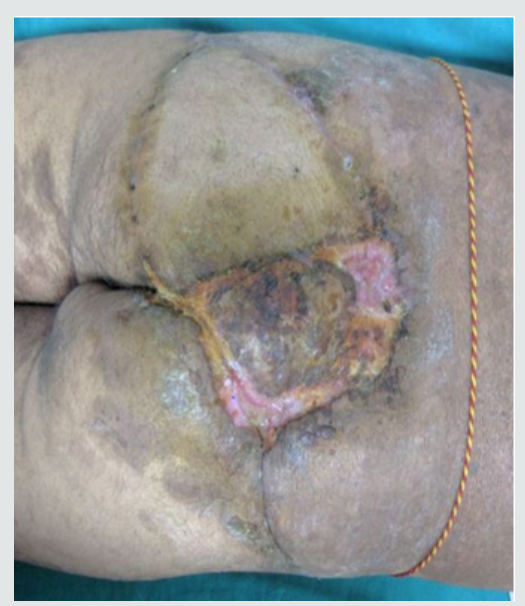

Figure 5: Figure showing flap coverage of the sacral defect with minor graft loss which healed secondarily.

\section{Discussion}

The relationship between psoriasis and increased cancer risk is debated. There may be an increased risk of some solid cancers in psoriasis: respiratory tract; upper aerodigestive tract ;urinary tract cancer; liver. The risk of non-Hodgkin lymphoma appears slightly increased in psoriasis. Psoriasis patients have an increased risk of squamous cell carcinoma and basal cell carcinoma whereas the risk of melanoma is not increased [4]. Psoriatic skin is known to have healing issues which should be kept in mind while deciding 
the reconstructive plan. In our patient there were psoriatic patches all around the defect involving back and buttocks except on the left side which was used for VY advancement flap. Furukawa et al reported the use of the Gluteus Maximus adipomuscular turnover and sliding flaps for sacral defects. The advantages of using the Gluteus Maximus muscle are its bulk; proximity to the defect; and robust blood supply [5-8]. Ohjimi H et al. [9] in 1996 concluded that the gluteus V-Y advancement flap as a fasciocutaneous flap is superior to the conventional musculocutaneous flap method.

The Gluteus Maximus originates from the lateral sacrum and posterior superior iliac crest and inserts into the greater trochanter of the femur and iliotibial tract. It is shaped like a parallelogram. This is a type III muscle with two dominant pedicles (superior and inferior gluteal arteries). The superior and inferior gluteal vessels enter about $5 \mathrm{~cm}$ from the pelvic origin of the muscle; and the medial circumflex and the first perforating femoral artery enter the muscle close to the femoral attachment. There are extensive anastomoses between the gluteal system and the lumbar perforators [6]. Lateral position and deep location of the gluteal pedicles; robust collateral circulation; allows safe elevation of Gluteus Maximus flap. Based on superior gluteal arteries it can reach the ipsilateral ischium and sacrum. Gluteal muscle flaps have been described in various forms which include only skin rotation flaps; skin with gluteal fascia rotation; transposition and advancement flaps; gluteal muscle turnover or sliding flaps; and musculocutaneous gluteal sliding and advancement flaps $[5,6,9]$. In our case; the integrity of the vascular pedicle was confirmed by using hand held Doppler. Right gluteus maximus muscle was detached from the superior; inferior and lateral attachments and turned over towards midline; keeping the blood vessels intact. On the left side only VY fasciocutaneous flap was sufficient as the defect was less on left side [10].

\section{Conclusion}

We conclude that long standing psoriatic ulcer should always be assessed for conversion into malignancy. Psoriatic skin limits the use of local flaps. For the reconstruction of sacral region gluteus maximus turnover flap can be used; and it can be combined with other local flaps like VY advancement flap for reconstruction. Gluteal maximus muscle flaps can be used with various combinations with fasciocutaneous flaps for reconstruction of sacral defects.

\section{References}

1. Ashwin B Kuchekar (2011) Psoriasis: A comprehensive review. Int J of Pharm \& Life Sci (IJPLS) 2(6): 857-877.

2. Das J, Gangopadhyay A, Gupta M (2013) Multicentric squamous cell carcinoma arising on psoriatic plaque. Indian Journal of Dermatology 58(2):151-153.

3. Jeevankumar B Thappa DM, Joseph L, Karthikeyan K (2004) Squamous cell carcinoma arising over psoriatic skin lesion. Indian J Dermatol 49(3): 163-164.

4. Pouplard C, Brenaut E, Horreau C, Barnetche T, Misery L et al. (2013) Risk of cancer in psoriasis: a systematic review and meta-analysis of epidemiological studies. Journal of the European Academy of Dermatology and Venereology 27(3): 36-46.

5. Furukawa H, Yamamoto Y, Igawa HH, Sugihara T(2000) Gluteus maximus adipomuscular turnover or sliding flap in the surgical treatment of extensive sacral chordomas. Plast reconstruct Surg 105(3): 1013-1016.

6. Ramirez OM, Swartz WM, Futrell JW (1987) The gluteus maximus muscle: experimental and clinical considerations relevant to reconstruction in ambulatory patients. Br J Plast Surg 40(1): 1-10.

7. Parkash S, Banerjee S (1986) The total gluteus maximus rotation and other gluteus maximus musculocutaneous flaps in the treatment of pressure ulcers. Br J Plast Surg 39(1): 66-71.

8. Ramirez OM, Hurwitz DJ, Futrell JW (1984) The expansive gluteus maximus flap. Plast reconstruct Surg 74(6): 757-770.

9. Ohjimi H, Ogata K, Setsu Y, Haraga I (1996) Modification of the gluteus maximus V-Y advancement flap for sacral ulcers: the gluteal fasciocutaneous flap method. Plast Reconstr Surg 98(7): 1247-1252.

10. Ramirez OM, Orlando (1984) The sliding gluteus maximus myocutaneous flap: its relevance in ambulatory patients. Plast Reconstr Surg 74(1): 6875.
This work is licensed under Creative Commons Attribution 4.0 License

To Submit Your Article Click Here: Submit Article

DOI: $10.32474 /$ SCSOAJ.2019.02.000126

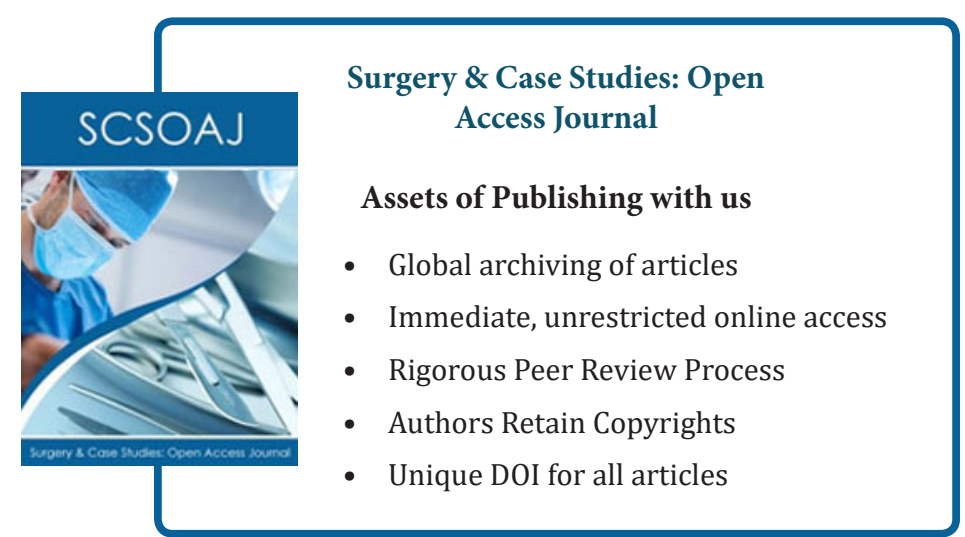

Citation: Naveen k, Shobhit G. Sacral Squamous Cell Carcinoma in Psoriatic Lesion: Reconstruction by Combined Gluteal Turnover and 